\title{
THE PASS EFFICIENCY OF MIDFIELD PLAYERS IS CORRELATED WITH GOALS SCORED IN MODERN FOOTBALL
}

\author{
Ciprian PANAIT ${ }^{*}$, Jeferson COLARES ${ }^{2}$ \\ ${ }^{1}$ National University of Physical Education and Sport, Faculty of Physical Education and Sport, Bucharest, \\ Romania \\ ${ }^{2}$ Federal University of Minas Gerais, School of Physical Education, Physiotherapy and Occupational Therapy, \\ Belo Horizonte, Brazil \\ *Corresponding author: cipi.rapid@yahoo.com
}

https://doi.org/10.35189/dpeskj.2020.59.3.2

\begin{abstract}
In modern football, having the ball is not tantamount to success. Following this study, we aim to analyse the efficiency of passes transmitted by the players specialised in the position of midfielder, referring specifically to some characteristic indicators of passes: direction, accuracy, distribution. It should be noted that this study was conducted on a football team in the Professional Championship of the Kingdom of Saudi Arabia. The research consisted in analysing the performance of midfielders in official games and establishing a relationship between the aforementioned characteristic indicators of passes and the concrete way in which the team created opportunities to score or scored goals. Thus, after determining the limits and capabilities of the team and players, we scheduled, in each training microcycle, the means to increase the efficiency of passes transmitted by the players specialised in the midfielder position. In particular, we used some means to get the midfielders to transmit the ball forward, from as few touches as possible, in the free space or directly to the striker. All means were designed for a dual purpose: technical and tactical. In conclusion, we can say that the direction, accuracy, and distribution of passes transmitted by the midfielders have a decisive role in creating opportunities and scoring goals.
\end{abstract}

Keywords: pass, midfield player, efficiency, goal.

\section{Introduction}

Football has been and will be a leading sport, which has come to determine social life in the last decade. Thus, the accelerated development of the game was achieved on a scientific basis and by improving the individual level of the players.

The 20th century, with its last decades characterised by an extraordinary pace of development in all fields, has also strongly influenced the social activities of mankind. In this context, sport, and especially the game of football, has become a powerful social phenomenon, with broad implications on the political, economic, and social realms at national and world levels. This has contributed even more to the development and refinement of the game of football.

At the beginning of the third millennium, football has come to be known as a game where major interests are manifested, a game of great attractiveness and popularity on all the meridians of the globe, which is evident and undisputed throughout the world.

Today, we find, following our practical experience as professional coaches, that the problem of preparing players for great performance is sometimes treated superficially, and other times there are excesses in the training programme, which have no practical effect in 
the official game and implicitly on the result. This should be approached with responsibility, and the entire complex training activity should be rethought in the smallest details.

That is why we believe that players should be treated differently, and the well-designed and systematised preparation process should ultimately result in the increase of the individual level of the players, who can put into practice the tactical plan of the coach, without requiring extended time for implementation.

In modern football, having the ball is not equivalent to success. Following this study, we aim to analyse the effectiveness of passes transmitted by the players specialised as midfielders, referring specifically to some characteristic indicators of passes: direction, accuracy, distribution.

We consider these indicators to be decisive, because, for example, accurate passing not only retains possession but may also lead to scoring opportunities while also restricting opposition possessions and scoring opportunities (Redwood-Brown, 2008). A pass was deemed accurate when it was received by a teammate, while it was deemed inaccurate when it was intercepted by an opponent (Kempe et al., 2018).

\section{Methodology}

The study was conducted on a football team in the Professional Championship of the Kingdom of Saudi Arabia. The research consisted in analysing the performance of midfielders in official games and establishing a relationship between the aforementioned characteristic indicators of passes and the concrete way in which the team created opportunities to score or scored goals. The scoring team showed a higher passing success rate in the 5 minutes before scoring a goal than the average for the half of the match in which the goal was scored (Redwood-Brown, 2008). Thus, after determining the limits and capabilities of the team and players, we scheduled, in each training microcycle, the means to increase the efficiency of passes transmitted by the players specialised in the midfielder position. Specifically, we used some means to get the midfielders to transmit the ball in front, from as few touches as possible, in the free space or directly to the striker to get the midfielders to pass the ball in front, from as few touches as possible, in the free space or directly to the striker. The key idea behind penetrative passing is for the attacking team to achieve a positional advantage over the defending team (Rein et al., 2017).

In order to understand exactly the nature of our approach, we need to highlight some defining aspects of the team on the basis of which the study was performed:

Our main topic of analysis was the effectiveness of the players specialised as central midfielders. The purpose was to determine the most effective actions of the midfielders when they were in possession of the ball so that the team could end up in the situation of scoring a goal. For example, a midfielder playing a lot of passes back towards the defence will have a high completion rate, but few of these passes would contribute to winning the games (McHale \& Relton, 2018). Thus, based on the experience gained in the previous season, we tried to increase the efficiency of the midfielders in the 2018-2019 season.

In the following lines, we will present some decisive aspects that characterised the team's performance in the training and games held in the last part of last season (the last 10 stages):

1. The available team had a lower value than in the previous season; 
2. Consequently, the tactical organization was determined by the value of the players, which led us to decide to use the 1-4-3-3 tactical system in most games;

3. Due to large fluctuations in player performance, the results obtained led to mental fatigue, so we changed the tactical organization in two games, using the 1-3-5-2 tactical system; therefore, the negative effect of mental fatigue on football-specific technical performance may also be related to the focusing of attention on irrelevant stimuli and a reduced ability to anticipate the movement of the ball and prepare to control it (Smith et al., 2015). As the football players' level of fatigue increases, their success in passing with accuracy decreases significantly (Mulazimoglu, 2014). The results demonstrate that footballspecific fatigue influences the performance of skills throughout simulated match play. More specifically, passing speed and shooting precision decrease throughout exercise (Russell et al., 2011).

However, in both systems used, we kept the tactical organization of the players in the middle of the field, constantly using 3 central midfielders, as can be seen in the picture (Figure 1):

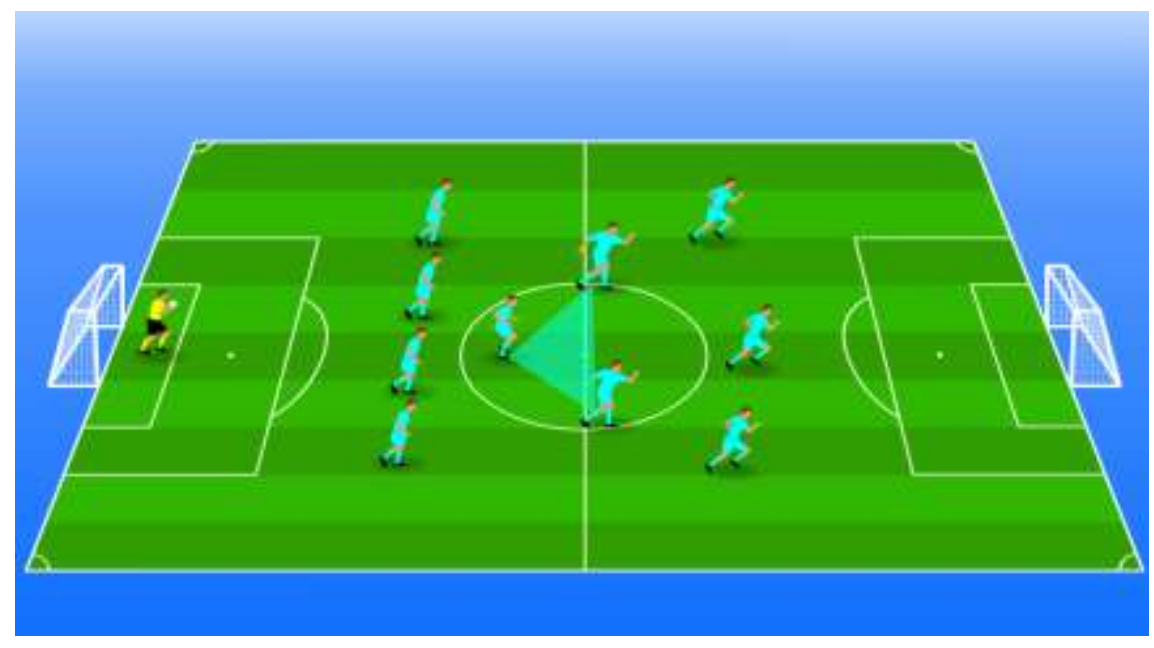

Figure 1. Midfield spectre

The tactical analysis of the team's performance highlighted the lack of efficiency of the midfielders, who did not have outstanding achievements during the game, which could be seen very quickly. According to Buldu et al. (2018), teams (beyond football and sports) need to generate new competencies such as systematic creativity and organizational learning that allow them to anticipate to the competition, promote their superiority and to create order and optimal organizational structures but, at the same time, to generate "disorder" in the opponent with the aim of creating situations of superiority.

Therefore, we believe that, in today's football, it is no longer enough for the player to possess a brilliant technique if it cannot be applied under the new conditions imposed by the football game (speed, power, permanent movement, long distances, increased aggression, etc.).

As stated above, the technique must be subject to the requirements of the modern game and be applied under conditions of adversity. But to get here, we need to know a few factors 
that can help increase the speed of play. These are: the individual qualities of the players, the level of performance of the team, the game system. But, over all these conditions, the player's ability to make tactical decisions that render the technique more efficient has to be updated. Thus, appropriate decision-making was considered when the pass went to a member of own team who was unmarked and: a) directly or indirectly created a goal chance or; b) it was for a member of one's team that was in a better position than the opponent (Gantois et al., 2019).

Over the years, tactical decisions like preferred playing formation or game tactics have increased in complexity, and coaches' tactical abilities are under constant public scrutiny (Rein \& Memmert, 2016).

To understand, we bring an exercise to your attention:

If you were in the position of head coach of a professional team, what would you choose?

- A midfielder with an exceptional technique, but who passes without tactical efficiency only sideways or backwards;

- A midfielder with average technical ability, but who has tactical efficiency when in possession of the ball (transmits the ball in front to the striker, behind the opposing defenders).

We believe that this simple example can create a picture of what we set out to improve in the tactical level of the players we worked with.

In conclusion, when the midfielders are in possession of the ball, they need to assume the tactical responsibility of transmitting the ball in front to the strikers, in space or behind the opposing defenders.

In order to understand our main target, we present the structure and content of a training macrocycle, with games played every 7 days, in the 2018-2019 championship edition of the Professional League of the Kingdom of Saudi Arabia:

\section{Stage 21}

Day I Training - character:

- Recovery - players who played in the official match of stage 20;

- Intensive - players who did not play or were out of the team.

Day II Training - character:

- Recovery - players who played in the official match of stage 20;

- Extensive - players who did not play or were out of the team.

Day III Workout 1 - character:

- Intensive (short-intensity efforts).

Training 2 - character:

- Extensive.

Day IV Training - character:

- Intensive (intensive "long-lasting" efforts).

Day V Training - character:

- Extensive.

Day VI Training - character:

- Extensive - activation. 
In order to achieve the proposed objectives, we intervened in training by programming means with a precise purpose, which allowed us to increase the efficiency of the players specialised in the position of midfielder. Thus, these means were aimed at creating tactical situations that would cause the midfielders to transmit the ball in front, between the lines or in space. Given these requirements imposed on players, we intended to implement the following principles of the game:

- Transmission of the ball in front, as the first option of the game, immediately after winning the ball (offensive transition);

- Fast play, with as few touches as possible - to increase the speed of decision;

- Transmission of the ball between the lines or in space - possession - progression towards the opposing goal.

Based on these principles, we designed training means to help us achieve the training goals set for the midfielders.

Therefore, we will present in the following lines, in detail, the concept and means of training developed during the study:

\section{Stage 21 - Game 1}

\section{Training 1}

40 ' recovery training for players who played in the previous game

Intensive - for players who did not play in the previous game

-10' warm up - pass exercises

- $15^{\prime} 4 \mathrm{v} 4$ - possession; transition

- 15' 4 v $4+4$ game progression, finalisation

- 5' 2 v 2 finalisation from cross; 3' run $-12 \mathrm{~s} / 80 \mathrm{~m}$

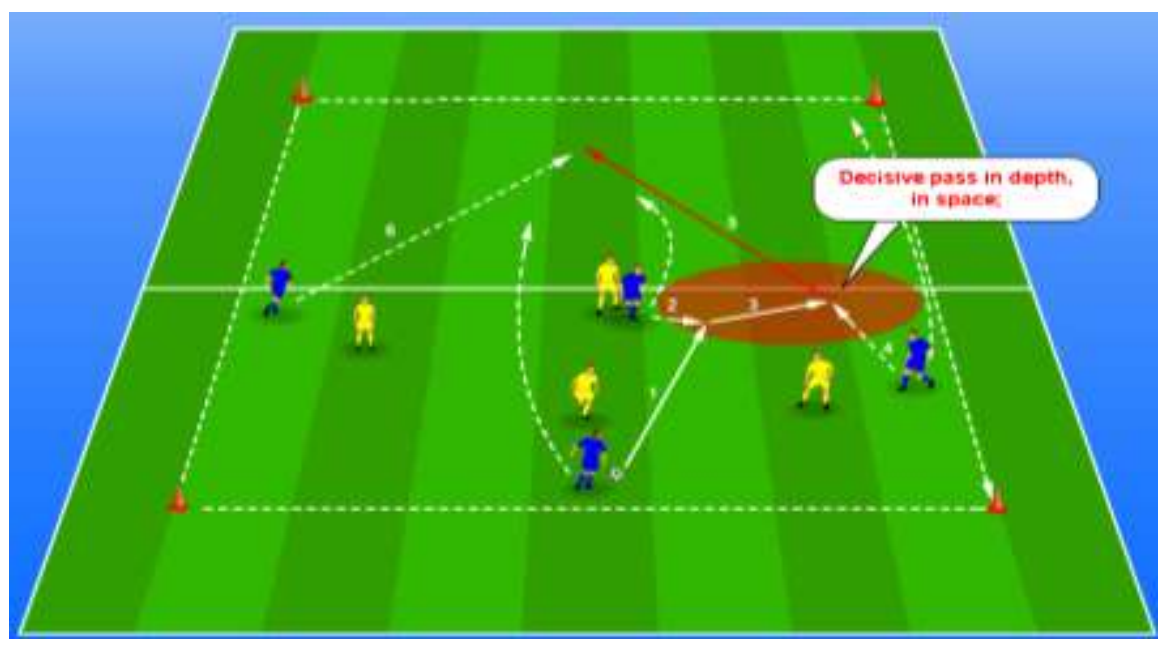

Figure 2. Small field game, 4 v 4

Tactical goal: pass in depth, fast offensive transition, attacking the space behind the opponents' line

Description (Figure 2): 
- 4 v 4 game inside a small field, 20 x $25 \mathrm{~m}$

- The game starts with one team in possession (blue), and the target is to pass the ball in front, on the other half, after 3 passes; if the team in possession (blue) succeeds, they get 1 point, but only if all the players of the team (blue) have arrived fast on the half of the field where the ball is.

- The team in defence (yellow) must press and close the ball, close the spaces and try to recover the ball as soon as possible; if they win the ball, they will earn 2 points, but only after the team passes the ball on the opposite side of the field and all the players (yellow) have arrived there.

Rules: the team with the ball has maximum 3 touches.

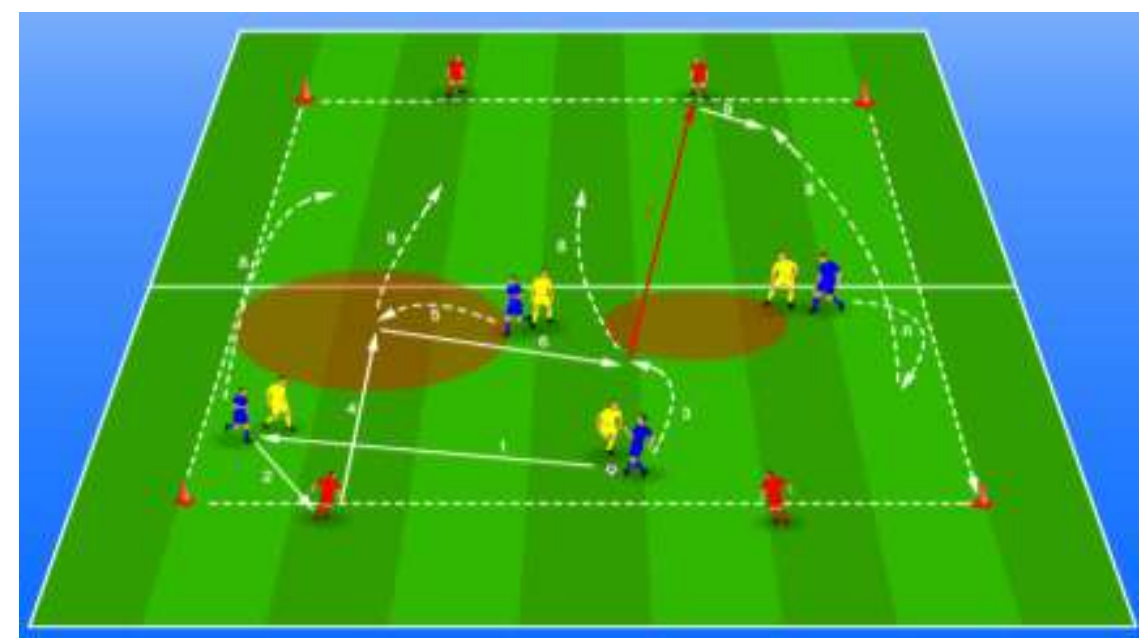

Figure 3. Small field game, 4 v $4+4$

Tactical goal: pass in depth, fast offensive transition, attacking the space behind the opponents' line and support from behind

Description (Figure 3):

- 4 v 4 + 4 game inside a small field, 20 × 25 m;

- the game starts with one team in possession (blue), and the target is to pass the ball in front, on the other half, after 3 passes, with the support of the red team; if the team in possession (blue) succeeds, they win 1 point, but only if all the players of the team (blue) have arrived fast in the other half to support the ball carrier;

- the team in defence (yellow) must press and close the ball, close the spaces and try to recover the ball as soon as possible; if they win the ball, they will earn 3 points, but only after the team passes the ball on the opposite side of the field and all the players (yellow) have arrived there.

Rules: the team with the ball have maximum 3 touches; the support players have 2 touches.

\section{Training 2}

Extensive

- 10' warm up - pass exercises; 3 midfielders' movement 
- 30' 7 v 6 - build up; 4 v 4 - offensive organization

- 15' tactical game, $10 \mathrm{v} 10$ (small field) - possession; progression; pass between

- $15^{\prime}$ tactical game, 11 v 11 (same above)

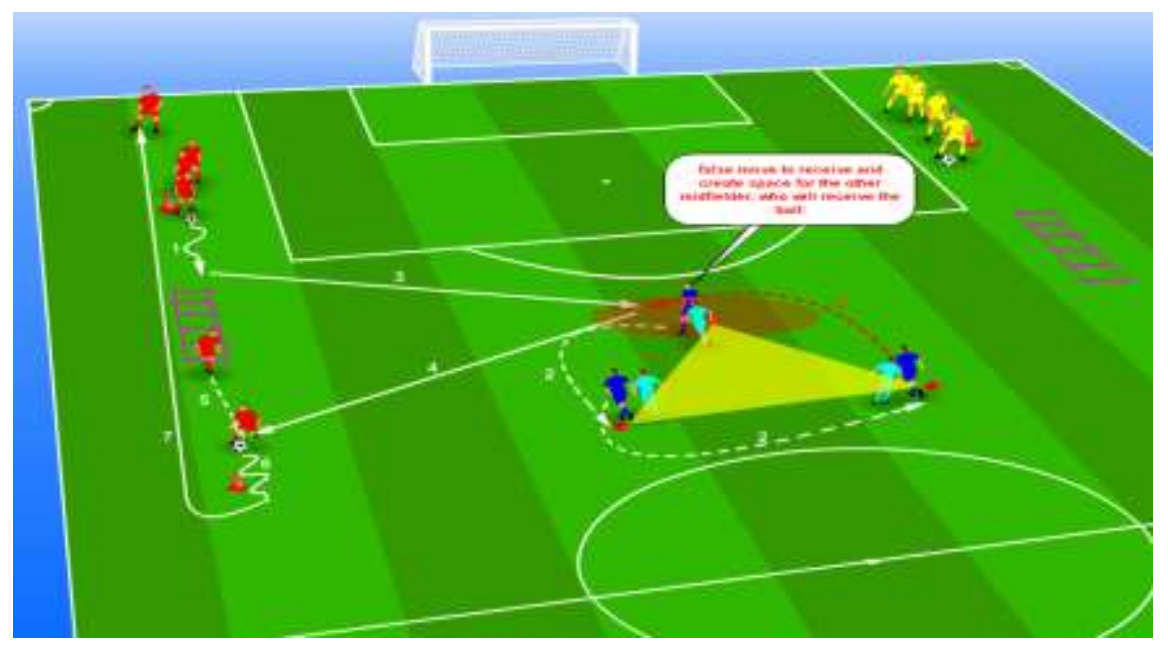

Figure 4. Passing exercise with 3 midfielders' movement

Tactical goal: creating the space for the midfielder to receive the ball; pass in the free space.

Description (Figure 4):

- The practice starts with one red player driving the ball.

- The blue midfielder must move to create space and receive, always keeping the triangle shape; after the blue midfielder has received the ball, he has 2 touches to pass in space.

- The blue midfielder must recover the position, covering the next free cone (counterclockwise movement).

- The light blue players are the opponents for the blue midfielders.

- The positions will be changed when the practice starts from the yellow player; then, the light blue will move to receive and create the space (clockwise movement), and the blue players become the opponents.

Rules: the midfielders must continue to move until the player in possession of the ball considers that he can pass safely in the created space; according to Lamche (2016), "On occasions where the pass is NOT 'on', it is vital that the rotating midfielder spin away, opening the space for the next midfielder to arrive" (p. 17). 


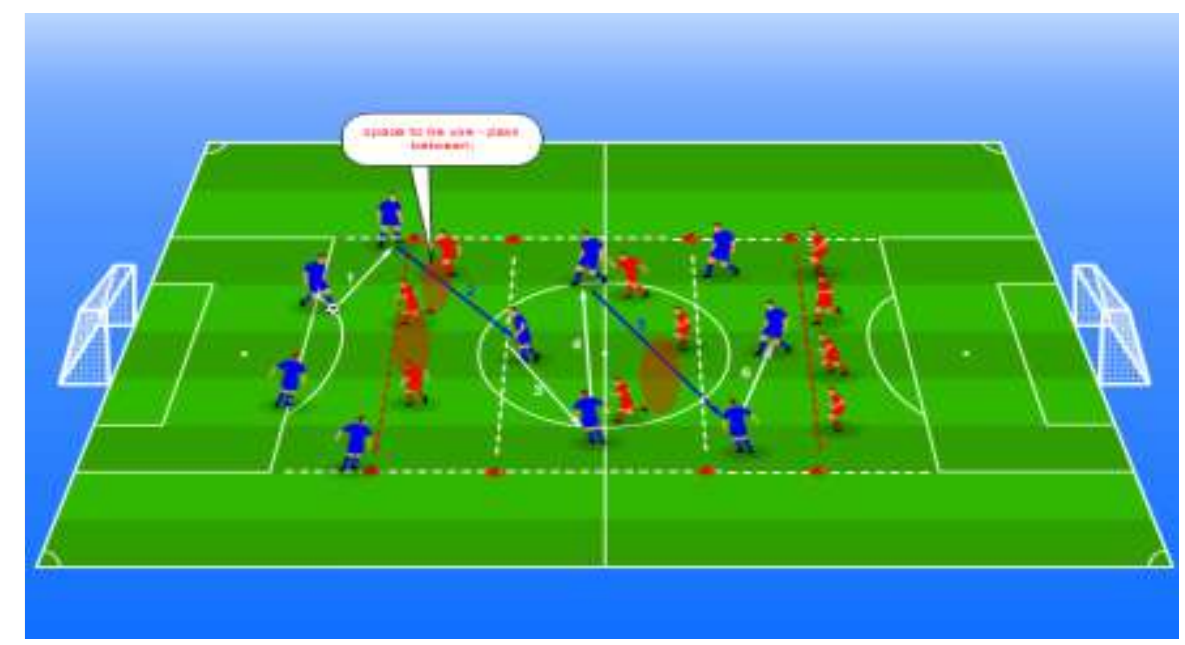

Figure $5.10 \mathrm{v} 10$ game - progression, pass between

Tactical goal: "play in front"; pass between the opponents; pass in-between the lines.

Description (Figure 5):

- The practice starts with the blue team defenders having the ball; they must pass the ball only between them until they can pass it between the opponents to the midfielders.

- The game continues with the blue midfielders passing the ball in front between the opposing midfielder's line to the attacking players.

- The blue team wins one point when the ball is passed from defenders to strikers and back, without the red team recovering the ball.

- If the red team wins the ball, they must do the same as the blue team when they have the ball.

Rules:

- The players cannot leave the designated area.

- The team that has the ball must use the entire width of the field to force the defenders to leave spaces between them; they have only 2 touches to pass the ball.

- The defending team must close the ball and the spaces between the players.

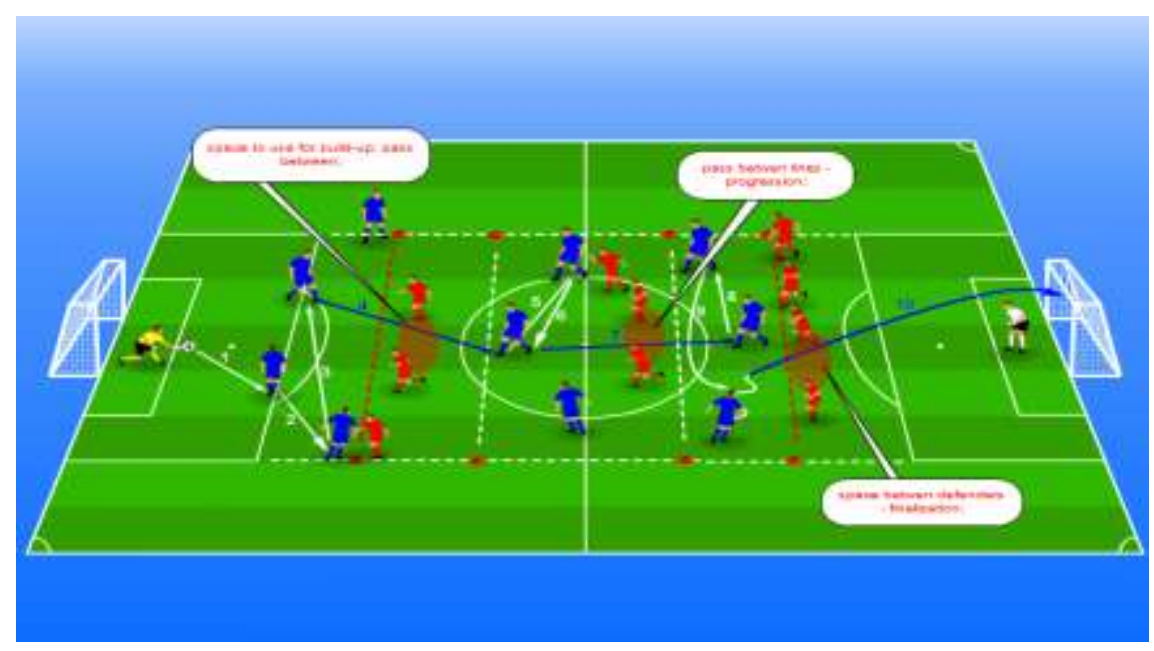

Figure 6.11 v 11 game - progression, pass between, finalisation 
Tactical goal: "play in front"; pass between the opponents; pass in-between the lines; finalisation.

Description (Figure 6):

- The game starts with the blue team goalkeeper having the ball.

- The blue team must pass the ball only between them until they can pass the ball between the opponents to the midfielders, and from them, to the strikers.

- The game continues with the blue strikers trying to find a solution (space) to score.

- If the blue team scores, the game will start again from the blue goalkeeper.

- If the red team wins the ball, they must pass the ball to the strikers and try to score, following the same rules of the game.

Rules:

- The players cannot leave the designated area.

- The team that has the ball must use the entire width of the field to force the defenders to leave spaces between them; they have only 2 touches to pass the ball.

- The strikers, in the designated area, have unlimited touches.

- The defending team must close the ball and the spaces between the players.

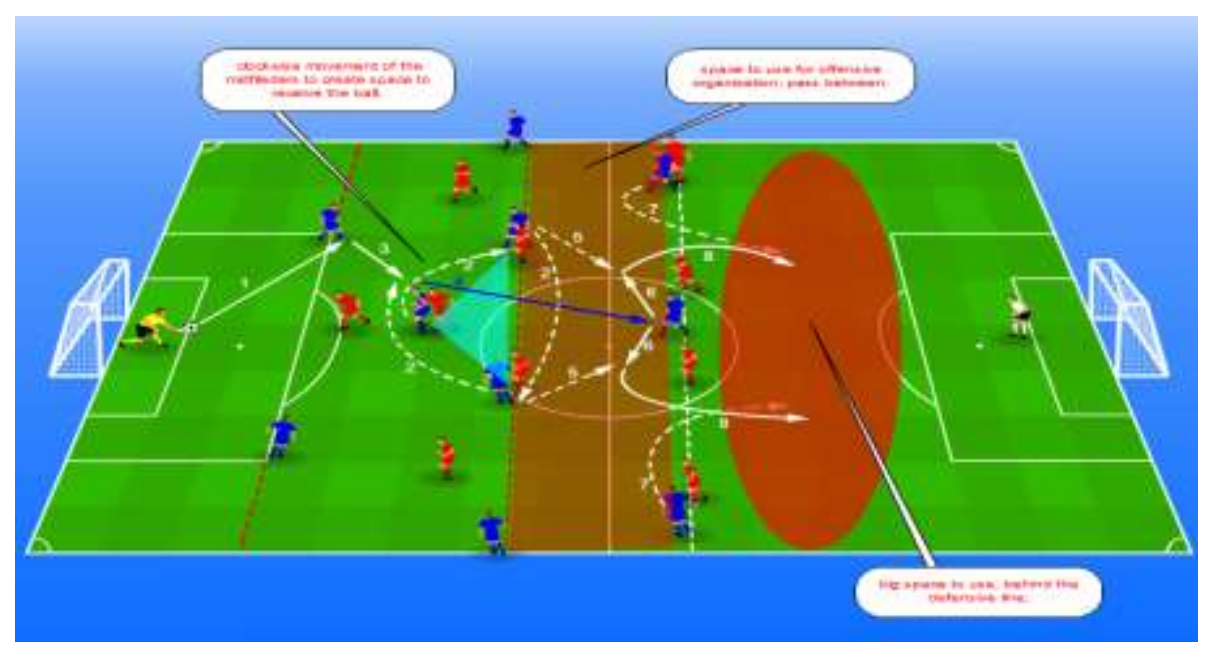

Figure 7.11 v 11 game - build up ( $\mathrm{v} 6$ ), pass between, offensive organization

Tactical goal: build-up against the opponents' pressing; pass between the opponents; pass in-between the lines; offensive organization; according to Tsokaktsidis (2014), "At the right time, one player moved and asked for the ball in behind the midfield to receive a pass from a teammate. This would take up to 6 opposition players out of the game, and that player would only have 4 defenders in front of him" (p. 99).

Description (Figure 7):

- The game starts with the blue team goalkeeper having the ball.

- The 4 blue defenders and the 3 midfielders must pass the ball to the strikers between the lines behind the opposing midfielders' line, playing against 6 opposing strikers and midfielders ( 7 blue v 6 red).

- The 3 blue midfielders must use the clockwise or counter-clockwise movement to create the space to receive the ball. 
- The 3 blue strikers must try to keep the line deep in the opposing field to create the space to receive between the lines.

- If the 7 blue players succeed to pass the ball between the lines overpassing the opponents' pressing, they start the offensive organization movement as follows: the 2 central midfielders go up to support the ball carrier, and the wingers start to run and ask for the ball in depth, behind the defensive line.

- If the red team wins the ball, they must use offensive transition and try to score.

Rules:

- In the build-up phase ( $7 \vee 6)$, the players cannot leave the designated area until the ball is passed in the space between the lines.

- The team that has the ball must use the entire width of the field to force the defenders to leave spaces between them; they have only 2 touches to pass the ball.

- In the build-up area, the blue team must perform at least 3 passes before they can pass the ball in front.

- The strikers, in the designated area, have unlimited touches.

- The defending team must close the ball and the spaces between the players.

\section{Training 3}

Extensive

- 10' warm up - ball

- 15,7 v $7+3$ (pass in depth)

- 15' tactical game - build up; offensive organization

- 15' finalisation (midfielders, strikers)

- 15 ' tactical-offensive play

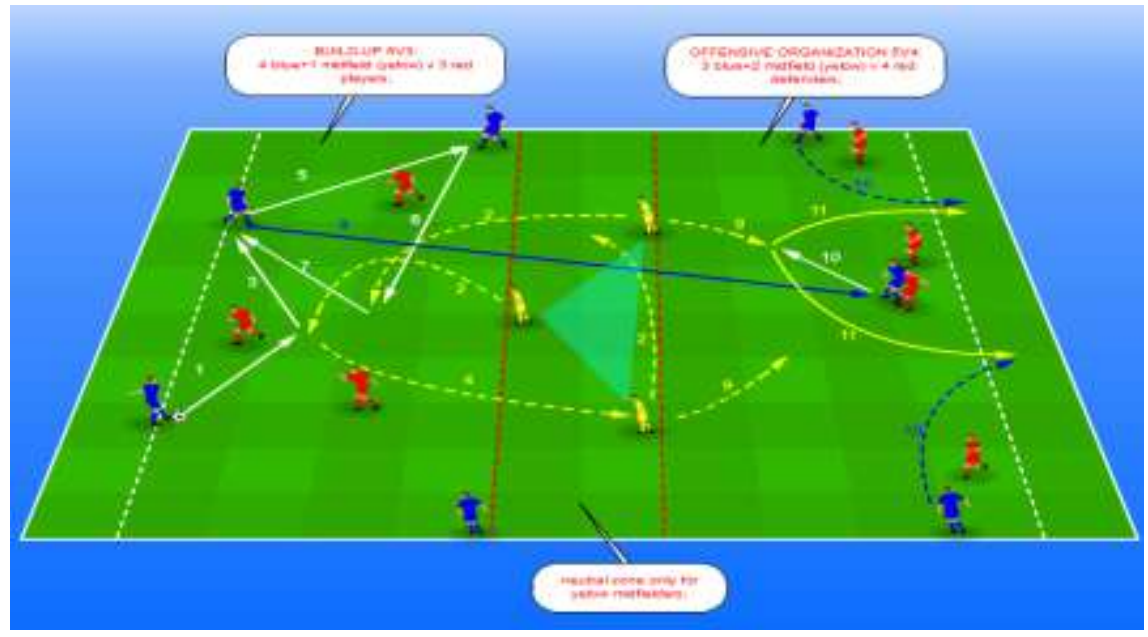

Figure 8.7 v $7+3$ game - build up, pass between, pass in depth

Tactical goal: build-up against the opponents' pressing; pass between the lines; pass in depth; coming from behind for support.

Description (Figure 8): 
- The game starts with the blue team having the ball and trying to build-up with the support of one yellow player.

- The 4 blue defenders and one yellow midfielder can pass the ball to the strikers between the lines, playing against 3 red opponents $(5 \vee 3)$ only after 3 passes in the build-up area.

- The 3 yellow midfielders must use the clockwise or counter-clockwise movement to create the space to receive the ball and be in a good position for the final pass; "Receiving a pass inside the area behind the opposition's midfielders with a body position that allows the player to face the opposition's goal could easily lead to a final pass" (Terzis, 2013, p. 33).

- The 3 blue strikers must try to keep the line deep in the opposing field to create the space to receive between the lines

- When the ball has arrived in the attack area, the 2 central midfielders go up to support the ball carrier, and the wingers start to run and ask for the ball in depth, behind the defensive line.

- If the red team wins the ball, they must play following the same rules.

Rules:

- In the build-up phase ( $5 \vee 3)$, the players cannot leave the designated area until the ball is passed in the space between the lines.

- The team that has the ball must use the entire width of the field to force the defenders to leave spaces between them; they have only 2 touches to pass the ball.

- In the build-up area, the blue team must perform at least 3 passes before they can pass the ball in front.

- The strikers, in the designated area, have unlimited touches.

- The defending team must close the ball and the spaces between the players.

- The team having the ball can win one point only if the ball is passed in the free space behind the opponents' defence line, and the ball is played (touched) there by a player of the team in attack.

\section{Training 4}

Extensive

- 10' warm up - ball

- 15' 8 v $8+8$ possession changing side; defensive transition

- 15' 11 v 11 game - pass between; finalisation

- 10' sprints over 10 m, 20 m

- 15' 3 v 2 game transition

- 20’ 6 v 6 small field game - tournament 


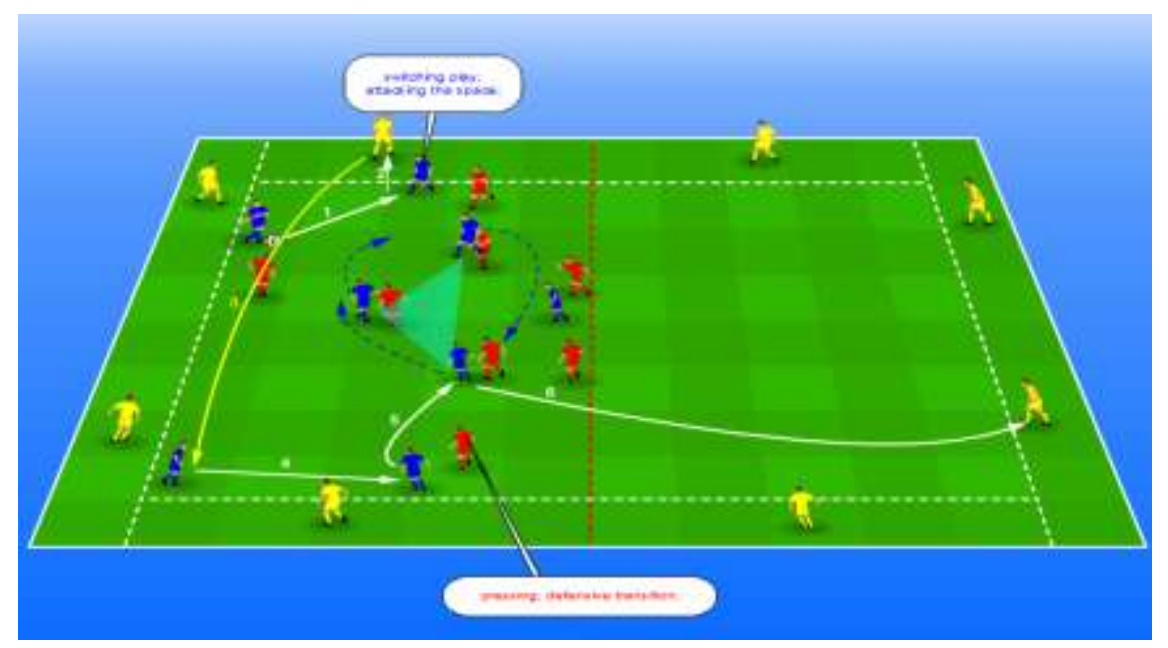

Figure 9.8 $8+8-$ switching play; defensive transition

Tactical goal: switching play; attacking the free space; coming from behind for support; defensive transition.

Description (Figure 9):

- The game starts with the blue team having the ball and trying to perform 5 passes with the support of the yellow team before switching play.

- The 3 blue midfielders must use the clockwise or counter-clockwise movement to create the space to receive the ball.

-When the ball has arrived in the other half of the field, the blue players must give support to the ball carrier, and the red team must make the defensive transition and try to win the ball.

- If the red team wins the ball, they must switch play to the other half and go to support the ball carrier, following the same rules.

Rules:

- The team that has the ball must use the entire width of the field to force the defenders to leave spaces between them; they have only 2 touches to pass the ball.

- The defending team must press aggressively to win the ball fast, in no more than 6 seconds, according to Tsokaktsidis (2017): this "tactic in the transition from attack to defence became known as the 6-second negative transition or the 6-second rule" (p. 17).

- The team having the ball can win one point only by switching play and receiving the ball again.

- The players from inside the field have 2 touches, and the support players have one touch. 


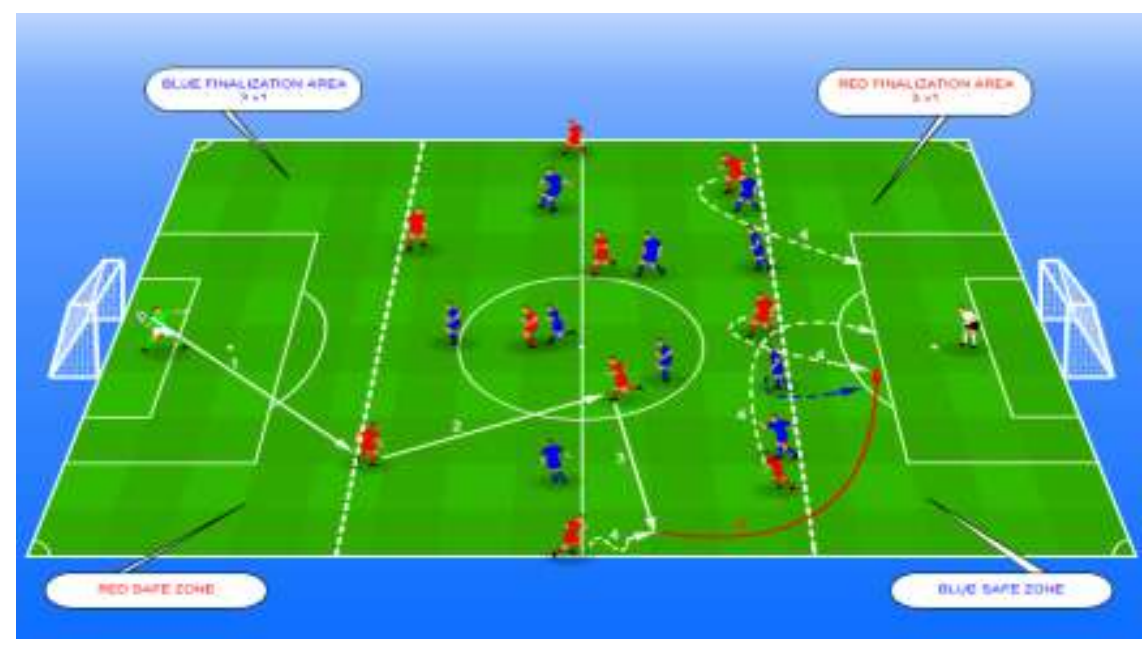

Figure 10. 11 v 11 - pass between; finalisation

Tactical goal: pass between and in depth; attacking the free space; coming from behind for support; finalisation.

Description (Figure 10):

- The game starts with the red team goalkeeper passing the ball to his defenders inside of the designated area.

- The red team must perform 4 passes before passing the ball in depth, in the finalisation area.

-When the ball has arrived in the finalisation area, only 3 players in attack and one defender are allowed to enter and play in that area.

- If the blue team wins the ball, they must play following the same rules.

Rules:

- Inside the middle area, the team in possession has only 2 touches.

- Inside the finalisation area, the strikers have unlimited touches but must finish the action in 4 seconds.

- No player can enter the finalisation area until the ball enters this zone.

\section{Results}

The statistical analysis of matches was performed with reference to the following:

1) Number of passes in front

2) Accuracy of passes in front

3) Distribution of these passes

The data are collected from reports provided by InStat Systems ${ }^{\mathrm{TM}}$, an online service that offers statistics of matches, with several data sources, through match analysis. All the data analysed refer to the block of 3 midfield players. The "attacks" term is used for team moments beyond the midfield line, according to InStat Systems ${ }^{\text {TM }}$.

One of the most important factors analysed in this study is the use of passes in front by the midfield players, and also the accuracy of this kind of passes. Table 1 shows the passes in 
front used by the block of three players along the 11 matches played. Also, this table shows the mean and standard deviation for these passes.

Table 1. Number of passes in front and their accuracy

\begin{tabular}{lccccccccccccc}
\hline & & & Match & Match & Match & Match & Match & Match & Match & Match & Match & Match & Match \\
& Mean & SD & 1 & 2 & 3 & 4 & 5 & 6 & 7 & 8 & 9 & 10 & 11 \\
\hline $\begin{array}{l}\text { P.F. } \\
\text { Acc. }\end{array}$ & 32.273 & 6.002 & 37 & 44 & 35 & 23 & 38 & 28 & 26 & 32 & 30 & 29 & 33 \\
P.F. (\%) & 56.00 & 11.00 & 65.35 & 70.86 & 56.36 & 60.98 & 66.26 & 37.62 & 48.59 & 55.95 & 55.00 & 61.03 & 39.55 \\
\hline P.F. (Passes in Front), Acc. P.F. (Accuracy of the Passes in front), SD (Standard Deviations) for this distribution
\end{tabular}

The chart in Figure 11 shows the distribution of these passes in the block of midfield players, and also their accuracy.

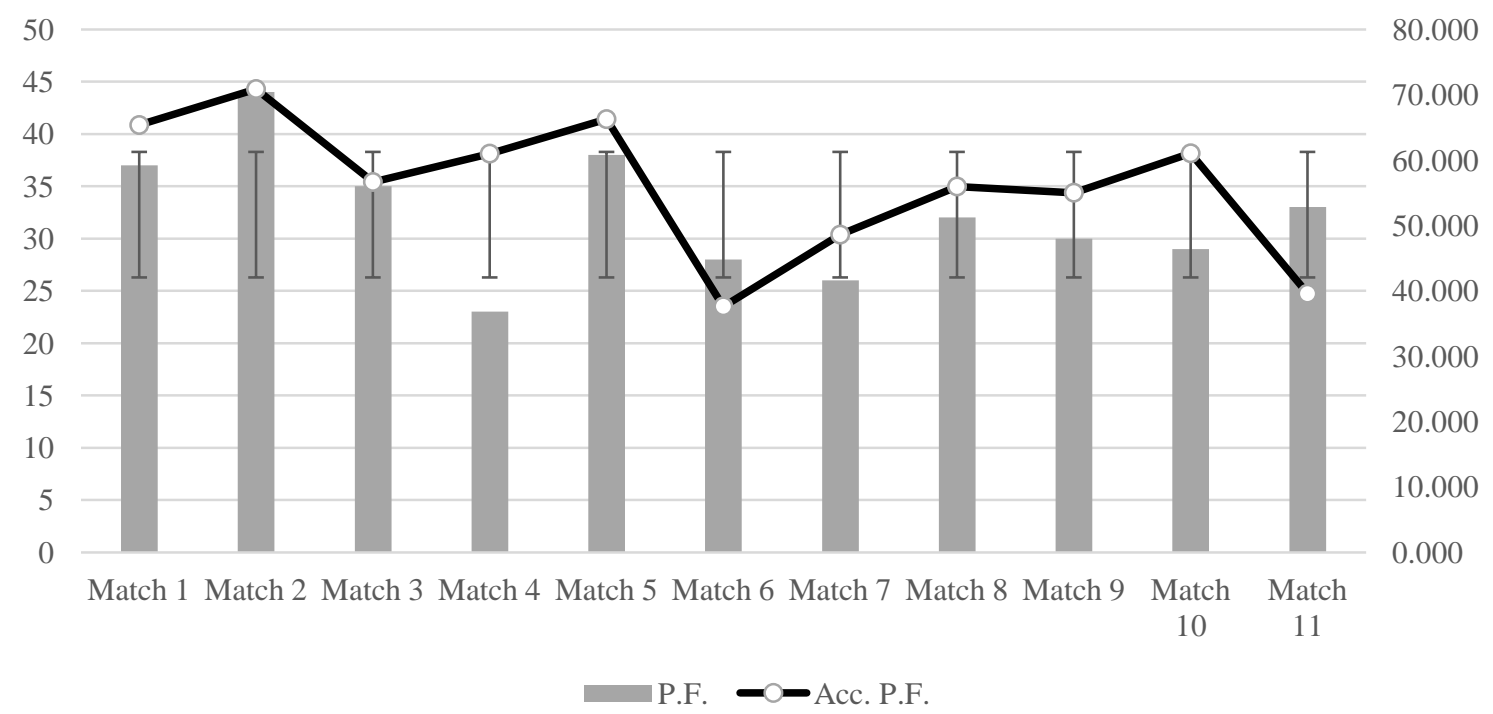

Figure 11. Total passes in front by the midfield players and their accuracy (Standard Deviation shown as lines through the bars)

The lines above the bars refer to the Standard Deviation of passes in front. The left scale refers to the number of passes in front, and the right scale, to the magnitude of passing accuracy.

Data show that, in match 2, the team had the major number of passes in front and also the best accuracy of these passes, although it did not reflect in more attacks in goals, as is going to be shown ahead in this work.

Table 2 shows the rate of passes in front over the total number of passes, and Figure 12 shows the accuracy of passes in front per player. It is important to see the attempts to advance in the game and the precision of these passes, as they are indispensable to reach the objective by creating scoring situations. 
Table 2. Rate of passes in front over the total number of passes

\begin{tabular}{|c|c|c|c|c|c|c|c|c|c|c|c|c|}
\hline Player & $\% \mathrm{~F}$ & $\begin{array}{c}\text { Match } \\
1\end{array}$ & $\begin{array}{l}\text { Match } \\
2\end{array}$ & $\begin{array}{c}\text { Match } \\
3\end{array}$ & $\begin{array}{c}\text { Match } \\
4\end{array}$ & $\begin{array}{c}\text { Match } \\
5\end{array}$ & $\begin{array}{l}\text { Match } \\
6\end{array}$ & $\begin{array}{c}\text { Match } \\
7\end{array}$ & $\begin{array}{c}\text { Match } \\
8\end{array}$ & $\begin{array}{c}\text { Match } \\
9\end{array}$ & $\begin{array}{c}\text { Match } \\
10\end{array}$ & $\begin{array}{c}\text { Match } \\
11\end{array}$ \\
\hline 5 & 34.67 & 34.38 & 48.57 & 55.00 & 40.74 & 50.00 & 51.72 & 11.93 & 46.67 & 48.39 & 29.27 & 32.50 \\
\hline 10 & 36.84 & 36.36 & & 40.00 & & & & & & & & \\
\hline 12 & 27.54 & 21.88 & 30.30 & 44.00 & 44.44 & & 28.00 & 7.02 & 37.84 & & & \\
\hline 20 & 29.03 & 40.00 & 48.48 & 36.67 & 0.00 & 36.67 & 25.00 & 3.17 & 16.67 & 31.25 & 42.50 & 41.67 \\
\hline 39 & 44.44 & & 100.00 & & & 42.11 & & & & 42.86 & & \\
\hline 80 & 13.18 & & & & & 28.57 & & & & 25.00 & & \\
\hline 32 & 13.04 & 50.00 & & & & & & 6.78 & & & & \\
\hline 77 & 33.33 & & & & & & & & & & & 33.33 \\
\hline
\end{tabular}

\section{Accuracy of passes in front per player}

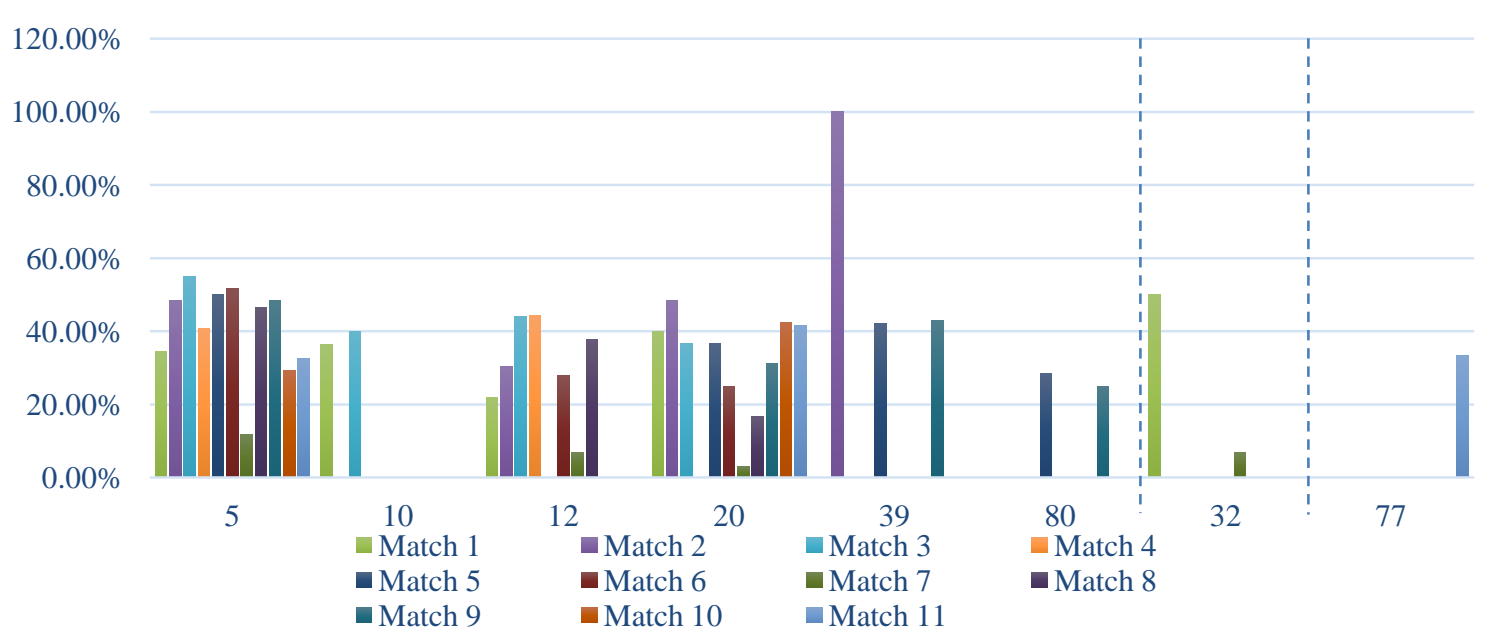

Figure 12. Accuracy of passes in front per player

It is clear that player 5 has more participation in these passes, followed by player 20 .

Another important variable is the path to reach the goal: how the team followed through the attack to reach it. Table 3 shows the origins of the attacks, scrutinising this path. The chart in Figure 13 illustrates these data. It is clear that positional attacks are the most used path to reach the goal.

Table 3. Origins of the attacks: how we reached the goal

\begin{tabular}{|c|c|c|c|c|c|c|c|c|c|c|c|}
\hline Attack type & $\begin{array}{c}\text { Match } \\
1\end{array}$ & $\begin{array}{c}\text { Match } \\
2\end{array}$ & $\begin{array}{c}\text { Match } \\
3\end{array}$ & $\begin{array}{c}\text { Match } \\
4\end{array}$ & $\begin{array}{c}\text { Match } \\
5\end{array}$ & $\begin{array}{c}\text { Match } \\
6\end{array}$ & $\begin{array}{c}\text { Match } \\
7\end{array}$ & $\begin{array}{c}\text { Match } \\
8\end{array}$ & $\begin{array}{l}\text { Match } \\
9\end{array}$ & $\begin{array}{c}\text { Match } \\
10\end{array}$ & $\begin{array}{c}\text { Match } \\
11\end{array}$ \\
\hline $\begin{array}{l}\text { Positional } \\
\text { attacks }\end{array}$ & 54 & 41 & 53 & 52 & 59 & 52 & 67 & 54 & 57 & 76 & 44 \\
\hline $\begin{array}{l}\text { Counter } \\
\text { attacks }\end{array}$ & 15 & 21 & 17 & 17 & 17 & 16 & 13 & 20 & 16 & 14 & 10 \\
\hline Set pieces & 10 & 12 & 5 & 18 & 8 & 7 & 12 & 15 & 10 & 11 & 7 \\
\hline
\end{tabular}




\begin{tabular}{|c|c|c|c|c|c|c|c|c|c|c|c|}
\hline $\begin{array}{l}\text { Free kick } \\
\text { shots }\end{array}$ & 3 & 1 & 1 & 1 & 1 & 1 & 1 & 0 & 1 & 1 & 1 \\
\hline $\begin{array}{l}\text { Free kick } \\
\text { combinations }\end{array}$ & 4 & 5 & 1 & 9 & 4 & 2 & 5 & 6 & 4 & 3 & 5 \\
\hline Corners & 3 & 6 & 3 & 8 & 1 & 4 & 5 & 6 & 4 & 6 & 1 \\
\hline Penalties & 0 & 0 & 0 & 0 & 0 & 0 & 0 & 1 & 1 & 1 & 0 \\
\hline
\end{tabular}

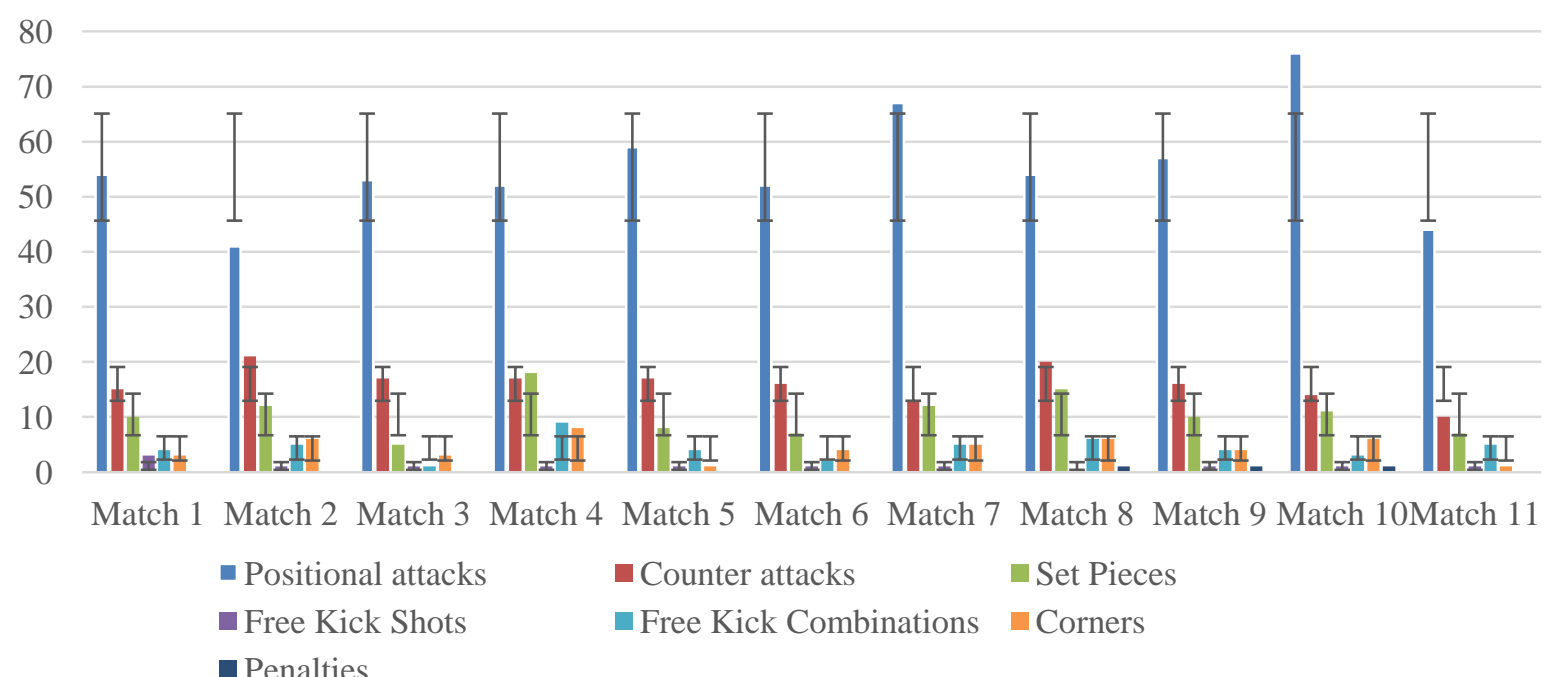

Figure 13. Origins of the attacks: how we reached the goal

(Standard Deviation shown as lines through the bars)

Table 4 and Figure 14 show the relation between attacks and attacks with shots. There is no logic progression between the number of attacks and their conversion into real scoring attempts.

Table 4. Relation between attacks and attacks with shots

\begin{tabular}{lccccccccccc}
\hline & Match & Match & Match & Match & Match & Match & Match & Match & Match & Match & Match \\
& 1 & 2 & 3 & 4 & 5 & 6 & 7 & 8 & 9 & 10 & 11 \\
\hline Attacks & 79 & 74 & 75 & 87 & 84 & 75 & 92 & 89 & 83 & 101 & 6 \\
Attacks & & & & & & & & & & 11 & \\
with shots & 8 & 7 & 6 & 9 & 7 & 11 & 10 & 14 & 13 & 14 & 5 \\
Rate (\%) & 9.875 & 10.571 & 12.500 & 9.667 & 12.000 & 6.818 & 9.200 & 6.357 & 6.385 & 7.214 & 12.200 \\
\hline Rate (\%): the rate of attacks with shots over the total number of attacks & & & & &
\end{tabular}




\section{Distribution of goals along the matches}

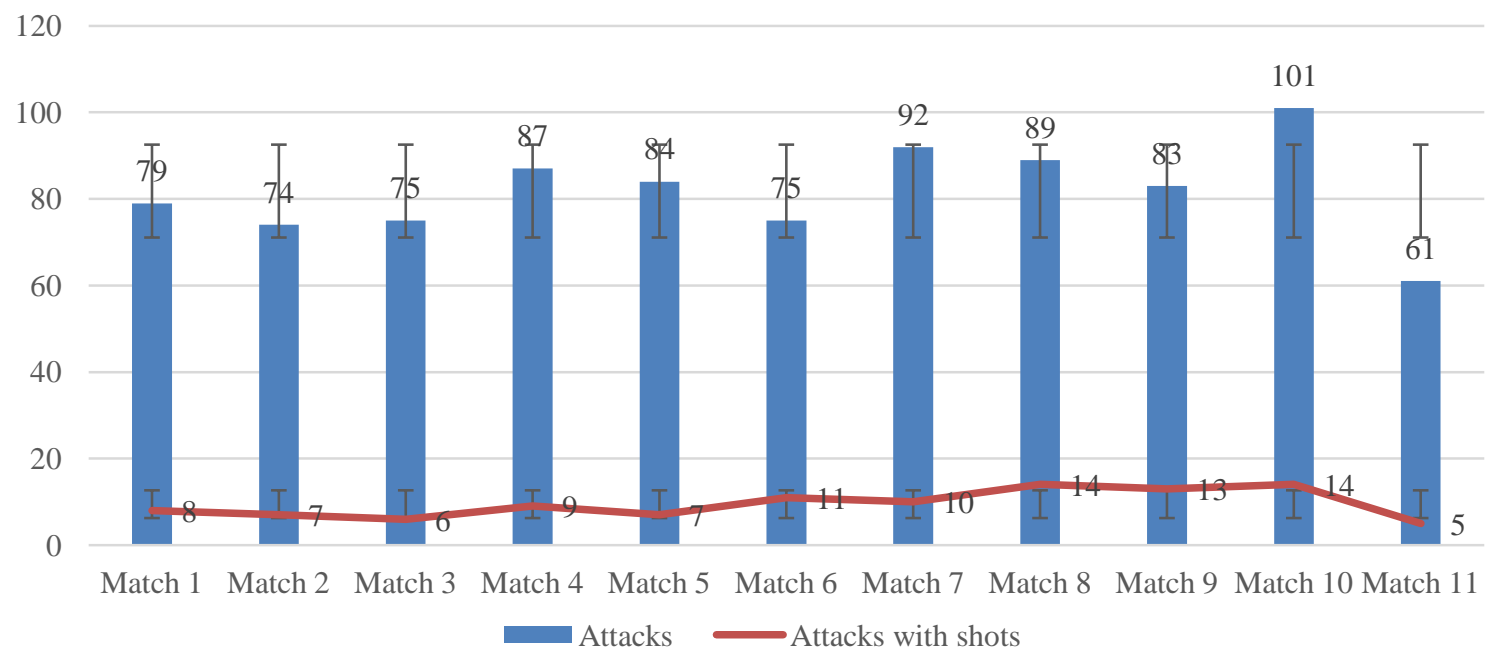

Figure 14. Relation between attacks and attacks with shots (Standard Deviation shown as lines through the bars and also through the line representing the attacks with shots)

Following the attack, the final part of a successful one is scoring a goal. The distribution of goals along the matches is shown in Table 5 and Figure 15 by their preceding type of action: positional attack, counterattack, free kick, corner kick and penalty.

Table 5. Distribution of goals along the matches

\begin{tabular}{|c|c|c|c|c|c|c|c|c|c|c|c|}
\hline Attack type & $\begin{array}{c}\text { Match } \\
1\end{array}$ & $\begin{array}{c}\text { Match } \\
2\end{array}$ & $\begin{array}{c}\text { Match } \\
3\end{array}$ & $\begin{array}{c}\text { Match } \\
4\end{array}$ & $\begin{array}{l}\text { Match } \\
5\end{array}$ & $\begin{array}{l}\text { Match } \\
6\end{array}$ & $\begin{array}{c}\text { Match } \\
7\end{array}$ & $\begin{array}{l}\text { Match } \\
8\end{array}$ & $\begin{array}{c}\text { Match } \\
9\end{array}$ & $\begin{array}{c}\text { Match } \\
10\end{array}$ & $\begin{array}{c}\text { Match } \\
11\end{array}$ \\
\hline $\begin{array}{l}\text { Positional } \\
\text { attack }\end{array}$ & 1 & 1 & 1 & & 1 & 2 & 1 & & & & \\
\hline $\begin{array}{l}\text { Counterattack } \\
\text { Free kick } \\
\text { Corner kick }\end{array}$ & & & 1 & & & 1 & & & 1 & & 1 \\
\hline Penalty & & & & & & & & 1 & 1 & & \\
\hline
\end{tabular}

3

2

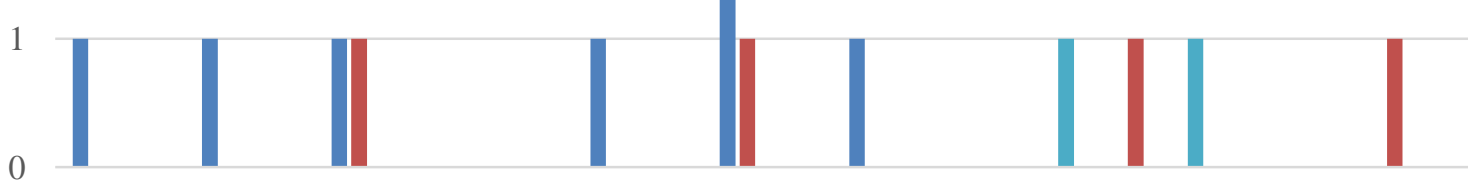

Match 1 Match 2 Match 3 Match 4 Match 5 Match 6 Match 7 Match 8 Match 9 Match Match

- Positional attack $\quad$ Counter attack $\quad$ Free Kick $\quad$ Corner kick $\quad$ Penalty

Figure 15. Distribution of goals along the matches (type of action) 
The positional attack is surely the most used to reach the opponent's goal. The total count of those goals is represented in Figure 16.

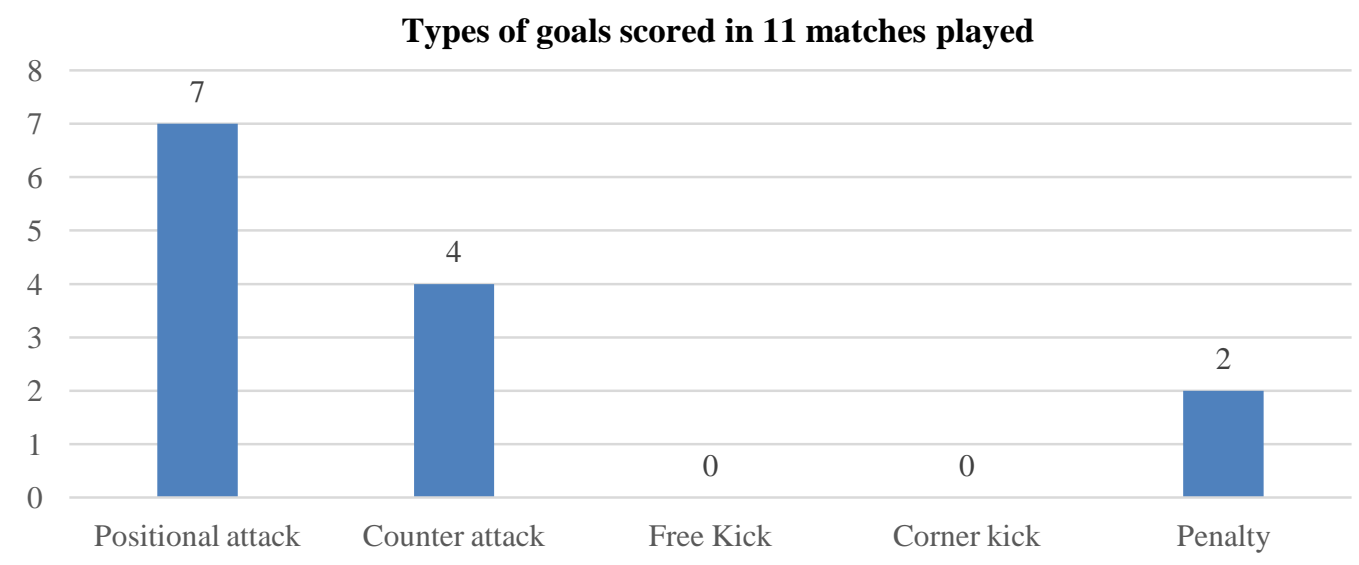

Figure 16. Types of goals scored in 11 matches played

It is clear that the positional attack was the most used to reach the goal successfully.

The data shown above lead to some preliminary conclusions:

In match 2, with 44 passes in front and $70.86 \%$ accuracy, the team attacked 74 times, with 7 attacks with shots. It was the highest level of accuracy of passes in front and also the highest number of passes in front. However, the number of attacks was not the highest one.

Match 10 showed only 29 passes in front, but with 101 attacks - the highest attacking rate, which could reflect the better decision-making of the players on passing with tactical intelligence to create attacking opportunities.

From the studies of other authors who addressed aspects related to the efficiency of passes (Rein et al., 2017), solutions to score goals or creating goal opportunities (McHale \& Relton, 2018), all highlighted by an enormous volume of statistical data (Bransen et al., 2019), we noted the following directions of analysis:

- All studies presented were of an observational nature, based on the statistical analysis of the data collected from official games.

- The authors analysed the overall and general efficiency of passes and all the decisive aspects of this tactical element; thus, no detailed analyses have been carried out on compartments or players specialising in certain positions; the passes were analysed mainly statistically and included all the players of the team.

- The data presented were brought to the attention of those interested in this field, without determining the tactical cause that influenced the results even more, without trying to give solutions to optimise tactical situations that might lead to the improvement of results in football.

Consequently, through this study, we continued the work of other authors, deepening the research from a different perspective as follows:

- The data presented by us have a targeted in-depth analysis of a single compartment players specialised as central midfielders.

- Our approach highlighted the decisive aspects of the game developed in the middle of the field by the players mentioned above, in the 1-4-3-3 tactical organization. 
- Our study contains specific and adapted training means and methods in order to optimise the performance of midfielders; these means were permanently subject to the stated tactical objectives:

a. transmission of the ball in front, as the first option of the game, immediately after winning the ball (offensive transition);

b. fast play, with as few touches as possible - to increase the speed of decision;

c. transmission of the ball between the lines or in space - possession - progression towards the opposing goal.

All these aspects give originality to our research and come to complete scientific research in the field. Last but not least, the ideas presented have a high degree of applicability, being tested in the professional football from an area with an accelerated development of sport in general and football in particular.

\section{Conclusion}

The results of official games, as well as the statistical analysis presented in this study, have led us to admit the following realities, which have the value of conclusions.

Although tactical and statistical analyses highlighted an increase in the quality of the game played by the midfielders, the team's results were not satisfactory. Of the 11 games that were analysed, we won only two and achieved only one draw, scoring only 13 goals.

The increase in effectiveness of the midfielders was obvious but not enough to win and score a bigger number of goals, which has led us to the following conclusions:

1. Tactical efficiency of the midfield players cannot have a decisive contribution in winning games unless it is matched with the contribution of the strikers in particular.

2. Although the means used in training to achieve the proposed objectives for the midfielders have proven their effectiveness, according to the statistics presented, we must recognize that our strategy, based on the optimisation and orientation of the midfielders' game, did not give the desired results. A concrete example is the second game in which the midfielders made the highest number of passes forward, 44, with the highest accuracy, $70.86 \%$. A game that ended with a draw, in which the team scored only one goal.

Only the orientation of the game in the middle of the field, directly towards the opposing goal, could not help the team win for the following reasons:

- Failure to cause major changes in the performance of the strikers, who could not adapt to the tactical change in the midfielders' tactical way of playing.

- The team's level of physical ability could not sustain such a game of midfielders, which was quickly oriented towards the opposing goal.

- The short time it took to increase the tactical and physical level of the team.

Given all these data, we can say without any doubt that the results depend on the efficient participation in the game of all players, even if the importance of the midfielders' performance is obvious. 


\section{References}

Bransen, L., Van Haaren, J., \& van de Velden, M. (2019). Measuring soccer players' contributions to chance creation by valuing their passes. Journal of Quantitative Analysis in Sports 15(2), 97-116. https://doi.org/10.1515/jqas-2018-0020

Buldu, M. J., Busquets, J., Martinez, H. J., Herrera-Diestra, J. L., Echegoyen, I., Galeano, J., \& Luque, J. (2018). Using network science to analyze football passing network: Dynamics, space, time, and the multilayer nature of the game. Frontiers in Psychology, 9: 1900. https://doi.org/10.3389/fpsyg.2018.01900

Gantois, P., Caputo Ferreira, M. E., de Lima-Junior, D., Nakamura, F. Y., Batista, G. R., Fonseca, F. S., \& de Sousa Fortes, L. (2019). Effects of mental fatigue on passing decision-making performance in professional soccer athletes. European Journal of Sport Science, 20(4), 534-543. https://doi.org/10.1080/17461391.2019.1656781

Kempe, M., Goes, F. R., \& Lemmink, K. A. P. M. (2018). Smart data scouting in professional soccer: Evaluating passing performance based on position tracking data. IEEE, $14^{\text {th }}$ International Conference on e-Science (pp. 409-410). https://doi.org/10.1109/eScience.2018.00126

Lamche, T. (2016). Coaching combination play from build up to finish. SoccerTutor.com Ltd.

McHale, I. G., \& Relton, S. D. (2018). Identifying key players in soccer teams using network analysis and pass difficulty. European Journal of Operational Research, 268(1), 339-347. https://doi.org/10.1016/j.ejor.2018.01.018

Mulazimoglu, O. (2014). An investigation of the effect of fatigue on passing accuracy in soccer players. International Journal of Academic Research, 6(2), 259-267. DOI: $10.7813 / 2075-4124.2014 / 6-2 / A .37$

Redwood-Brown, A. (2008). Passing patterns before and after goal scoring in FA Premier League soccer. International Journal of Performance Analysis in Sport, 8(3), 172-182. https://doi.org/10.1080/24748668.2008.11868458

Rein, R., \& Memmert, D. (2016). Big data and tactical analysis in elite soccer: Future challenges and opportunities for sports science. SpringerPlus, 5(1): 1410. https://doi.org/10.1186/s40064-016-3108-2

Rein, R., Raabe, D., \& Memmert, D. (2017). "Which pass is better?" Novel approaches to assess passing effectiveness in elite soccer. Human Movement Science, 55, 172-181. https://doi.org/10.1016/j.humov.2017.07.010

Russell, M., Benton, D., \& Kingsley, M. (2011). The effects of fatigue on soccer skills performed during a soccer match simulation. International Journal of Sports Physiology and Performance, 6(2), 221-233. https://doi.org/10.1123/ijspp.6.2.221

Smith, M. R., Coutts, A. J., Merlini, M., Deprez, D., Lenoir, M., \& Marcora, S. M. (2015). Mental fatigue impairs soccer-specific physical and technical performance. Medicine and Science in Sports and Exercise, 48(2), 267-276. https://doi.org/10.1249/mss.0000000000000762

Terzis, A. (2013). FC Barcelona training sessions. SoccerTutor.com Ltd.

Tsokaktsidis, M. (2017). Coaching transition play. SoccerTutor.com Ltd.

Tsokaktsidis, M. (2014). Spain attacking sessions. SoccerTutor.com Ltd. 